result leaves the reader with an understanding of the complexity of the problem, without the coherence of a single approach.

In many ways, this book fails to break out of the conventional molds for development and underdevelopment studies. For example, by choosing the concept of the "Third World" as the unit of his analysis, Lewellen steps into the quagmire that has hampered previous discussions. The intransigent nature of these problems calls for a new concept.

Both books offer useful perspectives on the current state of international affairs and world stratification. Whereas the former book provides the advanced social scientist with much to think about, the latter starts yet another generation thinking about the problem.

\title{
Feminist Political Ecology: Global Issues and Local Experiences. Dianne Rocheleau, Barbara Thomas- Slayter and Esther Wangari (eds) London and New York: Routledge, 1996. xviii, 327 pp.
}

\section{Reviewed by Helen Ross, Centre for Resource and Environmental Studies, Australian National University, Canberra.}

Given the theoretical contribution of gender studies to the field of political economy, this collection is a timely development in political ecology and in feminist theories. It is an equally useful set of case studies in development- -and especially sustainable development--studies, human ecology, anthropology, rural sociology, and social movements, well worth recommending to students in any of these fields as a course text.

In their opening chapter, the editors explain succinctly the positions and differences of a number of schools of feminist scholarship and activism on the environment. They describe their conceptual framework of 'feminist political ecology' as linking insights from feminist cultural ecology and political ecology with those of feminist geography and feminist political economy.

Feminist political ecology treats gender as a critical variable in shaping resource access and control, interacting with class, caste, race, culture, and ethnicity to shape processes of ecological change, the struggle of men and women to sustain ecologically viable livelihoods, and the prospects of any community for "sustainable development" (p. 4).

They focus on the gendered knowledge used in the creation and maintenance of healthy environments, gendered environmental rights and responsibilities, including property, resources, space, legal and customary rights, and gendered environmental politics and grassroots activism. These dimensions provide a general framework for analysis, around which the case studies are grouped.

Unusual for an edited collection, the case study chapters are almost seamless in their styles of analysis and writing. Most of the case studies artfully combine analytical comment with detail that enables one to visualise the situation.

Another strength of the organisation of the case studies is that whereas one theme, such as activism, predominates in each section, the other themes also permeate the analyses. For instance, Bru-Bistuer's Spanish case studies outlining women's participation in oppositional campaigns to industrial waste disposal also emphasises women's understandings of the environmental issues, focused on concerns for health. Miller, Hallstein and Quass' West Harlem case study describes a community (with substantial female leadership) that opposed the siting of a sewerage treatment plant in their area. It goes on to 
describe the health risks to women and children using the park subsequently built on the roof of the plant, owing to their gendered use of space. The other case studies emphasizing grassroots activism and gendered politics are Campbell's analysis with the women's group of Xapuri, of the extent and value of women's participation in the rubber tappers' union in far western Brazil, and Wastl-Walter's account of Austrian women's roles in grassroots opposition to the destruction of riverine forest on the Danube for hydroelectric power. In the latter case, the political campaign led to national changes in political participation, including an increase in women's participation.

In each of the sections, the juxtaposition of cases from industrialised and other countries is telling. The editors explain their wish to break down the stereotype that environmental issues in the so-called developing countries are a matter of survival, whereas in industrialised countries they are concerned with quality of life. The blend of case studies from different regions and ecosystems underlines commonalties in conditions and experience.

Gendered differentials in resource rights are examined through case studies on Kenya (Wangari, Thomas-Slayter and Rocheleau), the Philippines (Shields, Flora, Thomas-Slayter and Buenavista), and a central Himalayan valley (Mehta). For instance, the Kenyan case study explores the ways in which gendered customary rights to land and resources have interacted with colonial and postcolonial decisions on land tenure to increase women's alienation from the means of livelihood in semiarid regions. The case studies in this chapter also canvass gendered knowledge and famine response, and grassroots activism and self-help. A further example of rural women's diminishing control over access to cultivable lands and forests is provided for a Himalayan district in India. This case study also highlights how mountain farming systems are marginalised within national agricultural policy and research priorities. Like the Kenyan case, the Himalayan ownership rights--accruing to males, who are often absent--promote inequitable access to resources and structure women's dependence on men. This dependence, coupled with women becoming more marginalised from agricultural decision-making, and devaluation of their knowledge systems, leads to low social recognition for their roles in agriculture and affects food security.

The Philippines case study examines the effects of transition to a market economy on social exchange networks and practices, and the complex relationship between social exchange, gendered livelihoods and sustainable development. Women are central to the exchange networks. I particularly enjoyed the account of hog raising under the traditional exchange system and the market system. It reminded me of Lauriston Sharp's classic account of the social impacts of missionaries giving Australian Aboriginal women steel axes, where they had previously had to borrow stone axes from men under an elaborate social exchange system. Sharp's article could now be reread as gendered, if not feminist, political economy.

A section devoted to gendered forms of knowledge includes case studies in Zimbabwe (Fortmann), the Dominican Republic (Rocheleau, Ross, Morrobel), Silesia, Poland (Bellows), and the U.S.A (Seagar). These cases could have been grouped under activism. The Zimbabwe case study breaks the pattern of the other chapters by using the first person style, and describing participatory methods. The Dominican Republic case continues themes raised in other cases, that women's knowledge and practice of agriculture and forestry remain invisible, and that gendered interests are at stake in changing livelihood systems.

In another example that is as much about activism as about the combination of women's experiental knowledge with their scientific knowledge, the "tested food for Silesia program", founded by women, is described as a creative and pragmatic response to health and livelihood needs in a highly polluted region. The chapter speculates whether the movement will in time become "mainstreamed" and taken over by men. A final case study 
on the U.S.A discusses environmental activism against nuclear facilities. The knowledge theme is picked up in discussion as to whether women's strong roles in environmental activism reflect a female "ecoconnectedness", or can be explained in other ways. The chapter contrasts science-based with experience-based environmentalism, arguing that the former removes environmentalism from the realm of lived experience and undercuts the valuable environmental knowledge of local observers, marginalising women.

The final chapter identifies themes common to the case studies: (1) linking environment and survival, (2) the impact of large economic and political systems on localities, (3) asymmetrical gender-based entitlements to resources, (4) the value of local knowledge, (5) gendered rights over space and access to social and political power, (6) questioning of perceived divisions between rural and urban spaces and production systems, and (7) women's political struggles. These themes illustrate the editors' intentions to reject dualistic constructions of gender and environment, in favour of multiplicity and diversity, and an emphasis on the complexity and interconnectedness of ecological, economic, and cultural dimensions of environmental change. They amply illustrate the connections between global and local scales, in policies, processes, and practices.

Feminist Political Ecology provides an invitation to examine the power relationships that shape the environment through the insights of gender analysis, and a set of frameworks for doing so. It is far from a closed, or even finely crafted body of theory, more a description of common themes identifiable through this particular set of case studies and no doubt to be found in many other cases. This invites us to try out new ways of looking at gendered power relations in the shaping and use of the environment, while by no means attempting to have the last word. The work remains strongly grounded in the case material. The framework dimensions and theoretical insights are clearly drawn from these, and at all times in the theoretical chapters the case studies are used for illustration.

Among several lists of dimensions identified from the case studies, the editors outline four points as a basis for theory. These are

(1) recognition of the interconnectedness of all life and the relevance of power relations including gender relations in decision-making about the environment;

(2) questioning the presumption of technological progress and domination of nature;

(3) recognising that ideologies shape relationships among gender, knowledge, environment, and development--especially those formulated with a patriarchal mode--and that these create gendered access to information, knowledge, resources, and technologies for improving livelihoods; and

(4) addressing the different structural positions occupied by women and men, such as men's tendency to specialise, women's to pursue integrative roles in economic activity and resource management.

As a set of principles specifically identified to define a feminist political ecology, I found these less satisfactory than theoretical statements embedded elsewhere in the text. The defining characteristics are conjoined somewhat awkwardly with more general principles that are prominent in ecofeminism and common to a number of environmental philosophies and new paradigms within the traditional disciplines. This is just a matter of presentation. It illustrates that feminist political ecology is joining the groundswell of integrative thinking which has been emerging across many disciplines and interdisciplinary fields for the past quarter century. The important point is that recognition of gendered dimensions is still far from sufficient in the analytical and activist fields that recognise the interconnectedness of all life, and question the paradigm of technical progress and domination of nature. The theoretical strength of this book is less in this set of principles, than in the argument that gender interacts with (not merely adds to) the other dimensions of power relationships already recognised in political ecology. 
The editors recognise that in common with the majority of writing in political ecology and feminist scholarship, the book is primarily an analytical work, despite the degree of interest in analysing activism. The chapter on the Dominican Republic raises the important point that we need to move beyond critique to transform practice in land use and resource management. This is clearly the next challenging domain for feminist political ecology.

\section{Roads in the Sky: The Hopi Indians in a Century of Change, by Richard O. Clemmer. Boulder: West- view Press, 1995. xiv, 377 pp.}

\section{Reviewed by Marc Sills, Political Science Department, Metropolitan State University, Denver, Colorado}

This book is of great significance to anyone looking for an updated and comprehensive view of Hopi affairs, as well as to anyone even modestly sensitized to the questions raised by the Navajo relocation. Framed in a "world systems" model of global-local articulations, Roads in the Sky is also an essential addition to the bookshelves of American Indian policy scholars.

On a personal note, I began my graduate studies as a "Big Mountain partisan" (Clemmer's term). I was motivated at first by the alarms that were heard in the late 1970s and early 1980s, claims that Navajos (at Big Mountain, the reference is to Diné) subjected to the terms of the Navajo-Hopi Land Settlement Act of 1974 (PL 93-531) were victims of "genocide." How could this be "genocide", without machine guns and gas chambers and other means of mass murder? Eventually, I undertook a conceptual investigation of "ethnocide" (also referred to as "cultural genocide"), always with the Big Mountain question to orient my perspective (Sills 1992).

Are Hopis, as well as Navajos, victims of ethnocide? As Clemmer makes clear in this book, both peoples have suffered an immeasurable loss of control of their own destinies as a result of the policies to which they both have been subjected. But neither people has vanished, as was forecast only several decades ago; instead, they have both survived sufficiently to have developed successful resistance and revitalization strategies. Measuring and testing the balance of shifting countervailing forces of Hopi cultural life and death is the project that Clemmer has taken on. Confronting the full scope of these forces has required a clear-headed deciphering of the many contradictions of Hopi realities and, later in the book, their pertinence to the relocation. Clemmer is able to describe that tangle of issues with impressive clarity and insight. His book masterfully highlights the intricately interconnected clan, lineage, ceremonial, village, economic, political, social and personal relationships among Hopis. This richly textured fabric of social organization is situated within a shifting context of struggle over the allocation of political power, a colonial economy based on coal-mining, and Navajo neighbors whose presence is an obstacle to the full control of Hopi ancestral lands.

Roads in the Sky is anchored conceptually in the "world-systems" model of "modernization," a dynamic framework for analysis of neo-colonialism and neo-imperialism. Identifying the origins, the persistence, and observable manifestations of a peripheral 